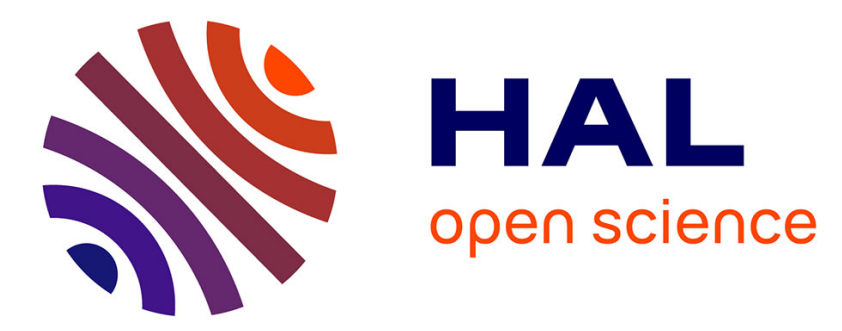

\title{
Transgenerational epigenetic sex determination: Environment experienced by female zebrafish affects offspring sex ratio
}

Fabien Pierron, Sophie Lorioux, Débora Héroin, Guillemine Daffe, Bruno

Etcheverria, Jérôme Cachot, Bénédicte Morin, Sylvie Dufour, Patrice

Gonzalez

\section{To cite this version:}

Fabien Pierron, Sophie Lorioux, Débora Héroin, Guillemine Daffe, Bruno Etcheverria, et al.. Transgenerational epigenetic sex determination: Environment experienced by female zebrafish affects offspring sex ratio. Environmental Pollution, 2021, 277, pp.116864. 10.1016/j.envpol.2021.116864 . hal-03434098

\author{
HAL Id: hal-03434098 \\ https://hal.science/hal-03434098
}

Submitted on 25 Nov 2021

HAL is a multi-disciplinary open access archive for the deposit and dissemination of scientific research documents, whether they are published or not. The documents may come from teaching and research institutions in France or abroad, or from public or private research centers.
L'archive ouverte pluridisciplinaire HAL, est destinée au dépôt et à la diffusion de documents scientifiques de niveau recherche, publiés ou non, émanant des établissements d'enseignement et de recherche français ou étrangers, des laboratoires publics ou privés. 
Main Manuscript for

Transgenerational epigenetic sex determination: environment experienced by female zebrafish affects offspring sex ratio

Fabien Pierron ${ }^{\mathrm{a}}$, Sophie Lorioux ${ }^{\mathrm{a}}$, Débora Heroin ${ }^{\mathrm{a}}$, Guillemine Daffe ${ }^{\mathrm{a}}$, Bruno Etcheverria ${ }^{\mathrm{a}}$, Jérôme Cachot ${ }^{\mathrm{a}}$, Bénédicte Morin ${ }^{\mathrm{a}}$, Sylvie Dufour ${ }^{\mathrm{b}}$, and Patrice Gonzalez ${ }^{\mathrm{a}}$.

${ }^{a}$ Univ. Bordeaux, CNRS, EPOC, EPHE, UMR 5805, F-33600 Pessac, France

${ }^{\mathrm{b}}$ Laboratory Biology of Aquatic Organisms and Ecosystems (BOREA), Muséum National d'Histoire Naturelle, CNRS, IRD, Sorbonne Université, Université de Caen Normandie, Université des Antilles, 75231 Paris Cedex 05, France

*Fabien Pierron

fabien.pierron@u-bordeaux.fr

\section{Orcid}

Fabien Pierron 0000-0001-6176-3050

\section{Classification}

Biological sciences

Environmental sciences

\section{Keywords}

DNA methylation, transgenerational, sex determination, plasticity, ecotoxicology

\section{Author Contributions}

F.P., J.C., B.M., S.D. and P.G. designed the research; F.P., S.L., D.H., G.D. and B.E. performed research; F.P. and S.L. analyzed data; F.P. wrote the paper.

\section{This PDF file includes:}

Main Text

Figures 1 to 6

\section{Abstract (250 words)}

Sex determination is a complex process that can be influenced by environment in various taxa. Disturbed environments can affect population sex ratios and thus threaten their viability. Emerging evidences support a role of epigenetic mechanisms, notably DNA methylation, in environmental sex determination (ESD). In this work, using zebrafish as model and a transgenerational experiment comprising 4 successive generations, we report a strength link between the promotor methylation level of three genes in female gonads and population sex ratio. One generation of zebrafish was exposed throughout its lifetime to cadmium (Cd), a non-essential metal. The subsequent generations were not exposed. At the first and the third generation a subset of individuals was exposed to an elevated temperature, a well-known masculinizing factor in zebrafish. While heat was associated to an increase in the methylation level of cyp19ala gene and population masculinization, foxl2a/dmrt methylation levels appeared to be influenced by cadmium (Cd) and density leading to offspring feminization. Ancestral $\mathrm{Cd}$ exposure indeed leads to a progressive feminization of the population across generations and affected the sex plastic response of zebrafish in 
response to heat. The effect of $\mathrm{Cd}$ on the methylation level of foxl2a was observed until the third generation, supporting potential transgenerational inheritance. Our results support the fact that the environment experienced by parents, namely mothers in the present case, can affect their offspring sex ratio via environment-induced DNA methylation changes in gonads. Our results also support a key role of cyp19ala methylation in ESD in zebrafish.

Significance Statement (120 words, Explain the significance of the research at a level understandable to an undergraduate-educated scientist outside their field of specialty)

In zebrafish, as in other various species, the sex (male or female) is not solely under the dependence of genetic components but can also be influenced by environmental cues. Disturbed environments can induce shift in population sex ratios. Underlying mechanisms remain elusive. Our results support a key role of DNA methylation, i.e. an epigenetic mechanism, in environmental sex determination in zebrafish. The DNA methylation levels of three genes known to be involved in gonadal sex differentiation and maintenance were found to be influenced by direct or ancestral exposure to cadmium, elevated temperature or fish density. Our results support the fact that the environment experienced by mother, grandmother or even great grandmother can affect the offspring sex ratio via environmentinduced DNA methylation changes in gonads.

\section{Main Text}

\section{Introduction}

Sex ratio (SR) represents a critical demographic parameter that affects the growth rate as well as the evolutionary trajectories of wild populations (1-3 West et al., 2002; Wedekind, 2012 and 2017). This parameter is directly under the dependence of sex determination (SD) mechanisms; i.e. the processes by which an organism initiates differentiation as a male or female. These processes are unexpectedly diverse among species and were traditionally and basically divided into two main categories: genetic sex determination (GSD) and environmental sex determination (ESD) (4 Capel, 2017). In organisms with GSD, the sex is determined by heritable genetic components whereas in organism with ESD, the sex is induced by environmental factors during early steps of development. Moreover, even if the sex of GSD species is normally inherited and fixed for life, the primary genetic sex can be challenged during early development in response to environmental factors in a such way that animal develop into the opposite sex of its genetic background. This phenomenon is relatively common in insects, fish, amphibians and reptiles (4 Capel, 2017). The most striking example of such phenomenon is temperature-dependent sex determination (TSD) where the thermal conditions experienced during the early stages of development of an organism influence its sex differentiation and development, determining irreversibly its gonadal sex at adulthood. Despite the mechanisms responsible for such plasticity, particularly in vertebrates, have long been unknown and remain a matter of debate, recent works, notably in fish (5-6 Shao et al., 2014, Navarro-Martin et al., 2011), would support a key role of epigenetic mechanisms, notably DNA methylation, in germline differentiation in response to high temperature (HT).

Epigenetics is the study of changes in gene function that are mitotically and/or meiotically heritable and that do not entail a change in the DNA code (7 Feil and Fraga, 2012). Epigenetic mechanisms by controlling the activity of genes play a key role in cell 
differentiation during development. One of the most studied epigenetic process, DNA methylation, is commonly associated with "gene silencing", i.e. transcriptional repression (with few exceptions; 8-9 Harris et al. 2018, Hammoud et al., 2014). During development cell differentiate, acquire and maintain identity by expressing a particular transcriptome (10 Piferrer, 2013). It is not surprising that such mechanisms could play a key role in SD. In gonochoristic species, SD indeed relies on the activation of one of the two developmental pathways (male or female) and shut down the other (4 Capel, 2017). There is increasing evidences that environmental factors such as nutrition, social interactions or temperature can strongly affect the epigenetic status of cells (7, 11-12 Feil and Fraga, 2012, Head et al., 2014; Jaenisch and Bird, 2003). By modulating the establishment and maintenance of epigenetics marks, environmental factors can influence the phenotype of organisms, a phenomenon by far the most documented in invertebrates (13 Kucharski et al., 2008). There is still a controversy in whether such environmental-induced changes in epigenetic marks can be inherited from one generation to the next, especially in vertebrates. The epigenome do not persist throughout life but undergo precise and coordinated changes at defined stage of development ( 7 Feil and Fraga, 2012). In mammals, both maternal and paternal genomes undergo extensive demethylation to reset the epigenome for totipotency during early embryonic development (14 Heard and Martienssen, 2014). However, in stark contrast to mammals, recent discoveries (15-16 Ortega-Recalde et al. 2019; Skvortsova et al. 2019) have reported that the germline of zebrafish does not undergo genome-wide erasure of DNA methylation at any stage of development, which could lead to transgenerational inheritance of environmental-induced epigenetic modifications in such non-mammalian species. In the half tongue, HT-induced methylation modifications in pseudomales (i.e. individuals with a female genetic background (ZW chromosomes) and a male phenotype) is globally inherited in their ZW offspring, which develop into pseudomales without further HT exposure (5 Shao et al., 2014). However, this does not represent a true epigenetic transgererationnal inheritance as the developing germ cells that gave rise to this generation were already exposed to HT as gametes in their parents.

There is increasing evidences that anthropogenic factors such as pollution can also lead to changes in the methylome of organisms. The defects or unintended changes in DNA methylation marks induced by pollutants can be associated with negative health outcomes such as embryonic lethality, tumor genesis, diabetes and infertility (7,11-12 Feil and Fraga, 2012, Head et al., 2014; Jaenisch and Bird, 2003). As epigenetic mechanisms play a key role in phenotypic plasticity, it could appear highly relevant to investigate whether pollutantinduced epigenetic modifications can impede the plasticity of an organism face to another stress, i.e. the establishment of an epigenetic response that aims to plastically adapt the organism to an environmental cue. Phenotypic plasticity represents the ability of a genotype to yield different phenotypes in response to an environmental stimulus. In other words, it represents the capability of an organism to change its physiology, morphology, behavior and even its sex to cope with variations in its environment. Phenotypic plasticity plays thus a central role in the persistence of populations (17 Fusco and Minelli, 2010). This appears especially true when the plastic trait is the sex of animals, linking individual phenotype to population structure. In this view, we must note that the theoretical advantage of TSD is to allow individuals to convert to the sex that offers the best fitness and reproductive success under prevailing thermal regimes (18 Spencer and Janzen, 2014). Moreover, past studies, even on taxa with GSD, have reported shifts in offspring SRs consistent with plastic adaptation (1 West et al., 2002). SR is not always random and parents can adjust the sex of their offspring to strategically maximize the fitness of their progeny according to the environmental conditions they experienced (1-2, 19-20 West, 2002; Komdeur et al., 1997; Wedekind, 2012, Shino, 2004). 
In this context, the aims of the present study were (i) to gain insight into the contribution of DNA methylation in ESD and (ii) to test whether direct or ancestral exposure to a pollutant could affect the plastic ESD response of organisms face to another stress via pollutant-induced epigenetic modifications. To test this hypothesis, we used wild-type zebrafish (Danio rerio). Despite the zebrafish is a popular model in many disciplines of biology, little is known about the primary mechanisms involved in SD and the subject still remain a matter of debate. Domesticated zebrafish lack identifiable heteromorphic sex chromosomes and sex is certainly polygenic (for review see 21-22 Liew and Organ, 2013; Nagabhushana and Mishra, 2016). Some influences from the environment were reported (23 Santos et al., 2017). Multiple factors like hypoxia, density, exposure to hormones and temperature were found to affect the SR. In all-genetic female zebrafish, exposure to HT at early stages of development leads to a complete masculinization of fish (24 Uchida et al., 2004). Ribas et al. (2017 25) also reported feminization of zebrafish treated with an inhibitor of DNA methyltransferase. One generation of zebrafish were exposed throughout their life, from fertilization until sexual maturity, to dissolved cadmium $(\mathrm{Cd}) . \mathrm{Cd}$ is a non-essential metal with estrogenic effects (26-27 Kortenkamp, 2011; Pierron et al., 2008) and that was previously found to affect the methylome of animals, including fish (28 Pierron et al. 2014). Rather than to expose fish at a defined stage of development, from far the most common approach, zebrafish were life-long exposed to $\mathrm{Cd}$ to encompass the remodeling events of DNA methylation that occur in germline during the embryolarval stage but also later in adult gonads at the onset of "puberty" (15-16, 29 Kesley and Feil, 2013; Ortega-Recalde et al. 2019; Skvortsova et al. 2019). At the first (direct exposure) and the third (transgenerational inheritance) generation, a subset of individuals was raised at an elevated temperature. The promoter methylation level of three genes (cyp19ala, foxl2a, dmrt1) involved in gonadal sex differentiation and maintenance were measured in the gonads of zebrafish. The gene cyp19ala, also called aromatase, encodes for the enzyme that converts androgens into estrogens. Previous works evidenced that aromatase could be a key player in the SR response to temperature in organisms with TSD (6 Navarro-Martin et al., 2011). Among the sexdetermining genes identified in zebrafish, forkhead box L2a (foxl2a) is involved in ovary maintenance (30 Yang et al. 2017) while doublesex and mad-3 related transcription factor 1 (dmrt1) was found necessary for testis development (31 Webster et al., 2017).

\section{Results and Discussion}

As the aim of this study was to investigate the transgenerational action of $\mathrm{Cd}$, only zebrafish from the first generation (F0) were exposed to dissolved $\mathrm{Cd}$ at an environmentally realistic concentration of $1 \mu \mathrm{g} . \mathrm{L}^{-1}$ (32 Couture et al. 2008) throughout their life, i.e. from the gamete to the adult stage. The next generations (F1, F2, F3) were not directly exposed to Cd (Fig. 1). DNA methylation analyses by bisulfite sequencing and transcription analyses by RTqPCR were carried out on gonads of 124-dpf-old fish. The SR of the population was determined at $170 \mathrm{dpf}$ (days post-fertilization). At the F0 and the F2 generation, a subset of individuals from different mating pairs was raised from $14 \mathrm{dpf}$ at an elevated temperature $\left(34^{\circ} \mathrm{C}\right)$. All these high temperature-treated fish $(\mathrm{HT})$ were analyzed at $130 \mathrm{dpf}$ and were not reproduced.

Masculinization of zebrafish in response to heat and transgenerational feminization in response to $\mathrm{Cd}$ 
At the first generation (F0), Cd exposure had no effect on the SR (Fig. 2). The SR of control (C) and Cd-exposed (Cd) fish reached 59.3 and $57.2 \%$, respectively. Such SR values are typically observed under experimental conditions. Indeed, the SR is generally around 60:40 (male to female) under normal laboratory conditions (23 Santos et al., 2017). The SR was then found to progressively and regularly decrease $(6.9 \%$ per generation) across generations in the case of fish transgenerationally exposed to $\mathrm{Cd}$, reaching $36.4 \%$ at the last generation (F3). In parallel the SR of $\mathrm{C}$ fish was constant until the $\mathrm{F} 2$ generation before to dramatically decrease at the F3 generation, reaching $39.1 \%$. This unexpected decrease will be further described. Thus, despite direct $\mathrm{Cd}$ exposure had no effect on sex determination in zebrafish, Cd affected transgenerationally the SR of zebrafish, leading to a progressive feminization of the population. Such an effect of Cd on SD was further supported by data obtained at HT.

At the F0 and F2 generations, a subset of individuals was raised at an elevated temperature $\left(34^{\circ} \mathrm{C}\right)$ from 14 to $130 \mathrm{dpf}$. As expected, HT was found to significantly increase the proportion of males in the case of $\mathrm{C}$ fish. The SR reached 88.6 and $91.0 \%$ at the F0 and F2 generations, respectively. $\mathrm{Cd}$ exposure or transgenerational $\mathrm{Cd}$ exposure was found to minimize the masculinizing effect of HT. At F0, SR values of CdHT fish were not statistically different from both fish raised at $27.7^{\circ} \mathrm{C}(\mathrm{C}$ or $\mathrm{Cd})$ and $\mathrm{CHT}$ fish. At the $\mathrm{F} 2$ generation, $\mathrm{Cd}$ fish raised at $34^{\circ} \mathrm{C}$ presented a SR that was equivalent to $\mathrm{C}$ fish raised at $27.7^{\circ} \mathrm{C}$, i.e. 62.7 and $61.2 \%$, respectively. Thus, both direct or transgenerational exposure to $\mathrm{Cd}$ affected the plasticity of fish and their SD in response to HT.

\section{Sex-specific DNA methylation and RNA transcription profiles}

Gender-specific DNA methylation and transcription profiles were observed for the 3 genes studied (Fig. 3A and 3B). A highly significant difference $(\mathrm{P}<0.0001)$ was observed between males and females (Fig. 3A). This appears in agreement with previous works carried on diverse fish species that reported sex dimorphic gonad expression of cyp19ala, foxl $2 a$ and $d m r t 1$ between sexes, including in danio (see 23 Santos et al., 2017 for review). In a lesser extent, previous works also reported sex dimorphic methylation levels of cyp 19ala and dmrt1 in fish gonads (33-34 Laing et al., 2018, Domingos et al., 2018). While cyp19ala is hypermethylated in males, dmrtl is hypermethylated in females. Despite foxl2 was found to be play a key role in fish ovarian differentiation and/or maintenance, the situation is less clear in literature and no gender-specific methylation patterns were reported to our knowledge (3435 Domingos et al., 2018., Anastasiadi et al., 2018). In our case, the methylation level of foxl $2 a$ was found to be significantly higher in females in comparison to males, whatever the generation or the condition (i.e. $\mathrm{C}$ or $\mathrm{Cd}$ ) considered.

A significant effect of temperature (Fig. 3A) was also observed on the three genes studied. However, this effect was mainly restricted to the DNA methylation data and to females. Concerning RNA, only the transcription level of foxl $2 a$ was found to be significantly influenced by HT in both males and females. The most important effect of temperature was observed on the DNA methylation level of cyp19ala. HT triggered a significant increase of cyp19ala methylation levels in females and on the contrary, a significant decrease in the case of males.

A significant effect of Cd was also observed (Fig. 3A). This effect was limited to the methylation levels of foxl $2 a$ in females of the first three generations and on the transcription level of cyp19ala in both males and females of the first three generations. This could appear in agreement with the fact that foxl 2 was identified as a transcriptional activator of cyp $19 a$ expression in diverse fish species (36-38 Fan et al., 2019; Zhang et al., 2017; Si et al. 2016). 


\section{DNA methylation of cyp191ala promotor as the key element of environmental sex determination}

To get more insight into the distinct role of the three genes in ESD, we also investigated the distribution of DNA methylation levels of these genes by pooling data from all generations. To more clearness, we used the normal density distribution of the data (Fig. 3B). However, raw data are available in Fig. S1. As we can observe in the Fig. 3B, a bimodal distribution clearly discriminating and separating males and females was observed only in the case of the cyp19ala gene. A threshold value of $\sim 66 \%$ was observed. Below this threshold, only females were observed and above, only males were observed. In the case of foxl $2 a$ or $d m r t 1$, in response to HT, males and females can present similar levels. We must note however that data from males and females raised at $27.7^{\circ} \mathrm{C}$ were clearly separated and a threshold around $15 \%$ and $12 \%$ for foxl $2 \mathrm{a}$ and dmrt 1 respectively could also be determined.

Aromatase appeared to be thus the main discriminating factor between the two sexes. This is consistent with the role of the cyp19ala gene that encodes for an enzyme responsible for the transformation of testosterone into estradiol. This suggests that cyp19ala could be the main effector of sex differentiation, at least in response to HT. This is also in agreement with the results obtained by 6 Navarro-Martin et al. (2011) in the European Seabass. Interestingly, as in our study, authors reported both (i) a significant increase in the methylation level of the gonadal cyp19a promoter in female European sea bass previously exposed to HT during early development (0-60 dpf) and (ii) clearly distinct frequency distributions between males and females with a threshold value of $67 \%$ (66\% in the present study). As the European sea bass, zebrafish are also classified as a gonochoristic species. Despite the mechanisms that control sex determination are still poorly understood in wild-type or laboratory strains of zebrafish, it 
is generally accepted that the ovarian development is a default pathway and that larvae and juveniles (from 0 to $21 \mathrm{dpf}$ ) initially develop an immature ovarian tissue independently of their genetic background (21-23). Afterwards, the ovarian tissue will be either maintained or undergo apoptosis, leading to the development of testis. In general, gonad differentiation begins from around $21 \mathrm{dpf}$ to be completed at $60 \mathrm{dpf}$. Thereafter, no sex reversal is observed. Moreover, intersex does not normally occur in danios that have already completed the sex differentiation process. In the same way, it has been proposed that exposure to endocrine disrupting chemicals (ECDs) have no effect on SR once phenotypic sex is established (with exceptions, see 23 Santos et al., 2017). Despite this subject is still a matter of debate, there is increasing evidences that the period from 0 to $60 \mathrm{dpf}$ constitutes a critical window of exposure during which the genetic sex of zebrafish can be challenged by environmental factors, notably by HT. In our case, zebrafish were exposed to HT from 0 to $124 \mathrm{dpf}$. However, in a previous work, 24 Uchida et al. (2003) reared wild-type zebrafish genetic females from 15 to 25 days post-hatching $(\mathrm{dph})$ at 3 temperatures $28.5,35$ and $37^{\circ} \mathrm{C}$. Before and after this sensitive period, all fish were reared at $28.5^{\circ} \mathrm{C}$. The percentage of masculinization in the genetic allfemales at $40 \mathrm{dph}$ at water temperatures of $28.5,35$ and $37^{\circ} \mathrm{C}$ were $0,68.8$ and $100 \%$, respectively. Dietary administration of a cytochrome P450 aromatase inhibitor to genetic females during the same sensitive period (15-25 dph) also resulted to a masculinization of fish at $40 \mathrm{dph}$. This study highlighted both the importance of the timing of exposure as well as the key role of cyp19ala in TSD in zebrafish.

In contrast to the study of Navarro-Martin et al. (2011 6), HT was not only associated with an increase of cyp19ala methylation levels in females but also and, at the opposite, with a decrease in the case of males. Cyp19ala methylation levels in $\mathrm{C}$ females increased significantly from $41.3 \pm 10.2 \%($ mean $\pm \mathrm{SE}, \mathrm{n}=24)$ to $51.0 \pm 6.6 \%($ mean $\pm \mathrm{SE}, \mathrm{n}=10)$ between 27.7 and $34^{\circ} \mathrm{C}$, respectively (Fig. S2). In parallel, the methylation level of cyp 19ala significantly decreased in males exposed to HT. Methylation levels of cyp19ala in C males raised at $27.7^{\circ} \mathrm{C}$ ranged from 90.0 to $97.4 \%(94.1 \pm 2.0 \%$, mean $\pm \mathrm{SE}, \mathrm{n}=24)$ and from 75.0 to $94.6 \%$ in males raised at $34^{\circ} \mathrm{C}(88.3 \pm 5.5 \%$, mean $\pm \mathrm{SE}, \mathrm{n}=16)$. While mean decreased significantly with increasing temperature, at the opposite, the variation among phenotypic males increased significantly (Levene test $p=0.002$ ) with increasing temperature. Such a decrease in mean associated to an increase in variance could be imputed to the contribution of pseudomales. Indeed, in response to HT, a significant proportion of genotypic females became phenotypic males (i.e. pseudomales). For recall, in response to HT, the SR of controls significantly increased from 59.3 to $88.6 \%$ at the F0 generation and from 61.2 to $91.0 \%$ at the F2 generation. The methylation levels of these pseudomales can be responsible to the decrease in the mean value of cyp19ala methylation levels measured in all-HT males in comparison to control males $\left(27.7^{\circ} \mathrm{C}\right)$. Thus, our results suggest that HT would be responsible for an increase in the methylation levels of cyp19ala during the thermosensitive period. Genotypic females that reach a methylation level of cyp19ala above a critical threshold (66\% at the adult stage in gonad) would become pseudomales. Data obtained from individuals directly or transgenerationally exposed to $\mathrm{Cd}$ can further support this hypothesis. Indeed, as previously described, Cd exposure minimized the masculinizing effect of HT at the SR level. No significant increase in cyp19ala methylation levels was observed in $\mathrm{Cd}$ females in response to HT. Moreover, the methylation levels reached by CdHT females was not significantly different from $\mathrm{C}$ females raised at 27.7 or $34^{\circ} \mathrm{C}$ (Fig. S2). Thus, if Cd minimized the effect of HT at the phenotype level, it also minimized the effect of HT-induced changes in the methylation levels of cyp19ala. As all larvae and juveniles (from 0 to $21 \mathrm{dpf}$ ) initially develop an immature ovarian tissue, it is intriguing to speculate that the methylation state of cyp 19ala during early stage of development plays a key role in sex determination. The apoptosis of the ovarian tissue during the period of gonad differentiation (21-60 dpf) would be 
linked to an increase in the methylation level of cyp19ala. This appears in agreement with a previous work that reported how the use of an inhibitor of DNA methyltransferase (5-aza-dC) induces feminization of zebrafish when the treatment coincides with the period of gonadal development (10-30 dpf, 25 Ribas et al., 2017).

\section{DNA methylation of foxl2a/dmrt1 in oocytes is a sensor of environmental cues affecting the offspring $S R$}

In order to get more insight into the role of the three genes and sex determination at the population level, we also tested for a potential correlation between DNA methylation or transcription levels and the SR among generations. A very high correlation was observed between the DNA methylation level of cyp19ala in female gonads and the SR (Fig. 5A). This appears quite surprising as such a correlation was established between the methylation level of one gene measured in 5-8 biological replicates per condition and the total number of adult fish produced at each generation $\left(n=303-663\right.$ per condition and generation at $27.7^{\circ} \mathrm{C}$ and $\mathrm{n}=$ 44-68 at $34^{\circ} \mathrm{C}$ ). No significant correlations were found with males, neither with transcript levels nor with the methylation levels of foxl $2 a$ and dmrt1. This again supports a key role of cyp 19ala methylation in sex determination. The question is: how is such relation possible? Subsequently, we also tested for a potential correlation between the same parameters at the generation $\mathrm{F}$ and the $\mathrm{SR}$ at the next generation $(\mathrm{F}+1)$. Unexpectedly, we also found a highly significant relationship between the DNA methylation of foxl $2 a$ in mother gonads and the SR of the offspring (Fig. 5B). We must note that fish raised at HT were not taken into account in this relation as they were not reproduced. Despite surprising, these results could appear in agreement with data obtained in species where shifts in offspring SR in response to the environmental conditions experienced by their parents were reported. Parents, especially mothers, are able to manipulate the SR of their offspring in response to ecological or social factors prevailing in their rearing environments (2, 18-20 Wedekind, 2012).

This latter result could explain, at least in part, why a transgenerational feminization of $\mathrm{Cd}$-zebrafish was observed across generations. In fact, a significant effect of $\mathrm{Cd}$ was observed on the methylation level of foxl $2 a$ across the F0, F1 and F2 generations. It appears intriguing to speculate that $\mathrm{Cd}$ by affecting the methylation levels of foxl $2 a$ in mothers affected the offspring SR. We must note that, despite the methylation level of foxl $2 a$ was significantly affected by $\mathrm{Cd}$ at the F0 generation, no effect of $\mathrm{Cd}$ was observed on the SR at this generation. Considering that sex is determined during the early stages of development, this could suggest that $\mathrm{Cd}$ mainly affected the methylation level of foxl $2 a$ in fully differentiated females of the F0 generation, during the maturation stage (23 Santos et al., 2017). In the same view and as the methylation level of cyp19ala plays a key and early role in SD, we then measured the methylation level of cyp191ala in the whole larvae (5 dpf) of each generation. A highly significant correlation was observed between the DNA methylation level of foxl2a in female gonads of the generation $\mathrm{F}$ and the methylation levels of cyp19ala in the larvae of the generation $\mathrm{F}+1$ (Fig. 5C). This could explain how changes in the methylation level of foxl $2 a$ in mother gonads can affect the SR of the offspring. In addition, a significant correlation was observed between the methylation level of cyp19lala in larvae and in female gonads of the same generation (i.e. from larval to adult stage; $r=0.904, P=0.002$, data not shown). This latter result could explain why a highly significant correlation was observed between the DNA methylation level of cyp19ala in female gonads and the SR at the same generation.

To get more insight, we then searched why the SR of controls dramatically drops at the F3 generation (Fig. 2). The only factor that was not similar among generations was fish density. Despite no significant difference in adult fish density was observed between control 
and Cd-exposed fish over the four generations, the density of fish was significantly two-fold higher in fish of the generation F2 (Tukey's HSD test, P $<0.05$, Fig. S3) in comparison to the other generations. Highly significant correlations were observed between fish density and the methylation levels of foxl2a or $d m r t 1$ in females (Fig. 6). We must note that despite all data, i.e. from both $\mathrm{C}$ and $\mathrm{Cd}$ fish, were considered in the case of $d m r t 1$, only data from $\mathrm{C}$ females were used for foxl $2 a$. Indeed, as previously described, while $\mathrm{Cd}$ did not affect the methylation level of $d m r t 1, \mathrm{Cd}$ significantly decreased the methylation levels of foxl $2 a$ from the F0 to the F2 generation. At the generation F3, this variable was found to be no further affected by $\mathrm{Cd}$. This effect is also observable in Fig. 6A. Such an effect of density on the methylation level of foxl $2 a$ and dmrtl undoubtedly reinforces the role of DNA methylation marks in mother gonads on the SD of their offspring. This appears especially true for dmrtl. Indeed, the promoter methylation level of this gene was found to be significantly (Tukey's HSD test, $\mathrm{P}<$ 0.05) lower in the female $\mathrm{C}$ fish of the generation $\mathrm{F} 2$ in comparison to $\mathrm{C}$ females of the other three generations (F0, F1 and F3).

Taken together, our results would suggest a role of ovarian promoter methylation state, notably of the couple foxl $2 \mathrm{a} / \mathrm{dmrt}$, as a sensor of environmental cues (Cd or density) and as a transgenerational "inducer" of SD in zebrafish. In response to $\mathrm{Cd}$ or density (i.e. social interactions), the methylation level of foxl $2 a / d m r t 1$ was significantly affected in female gonads. This tends to affect the methylation level of cyp19ala in the offspring as suggested by the significant correlation observed between the methylation state of foxl $2 a$ in mother gonads and the methylation level of cyp19ala in the larvae of the next generation. In both cases, i.e. in response to $\mathrm{Cd}$ exposure or to high density, feminization of the offspring can appear as an adaptive response. Indeed, at the end of the exposure period (170 dpf), a significant effect of $\mathrm{Cd}$ was observed on the Fulton condition factor ( $\mathrm{K}$, an index frequently used in ecology to assess the relative plumpness of fish) of male fish of the generation F0. While $\mathrm{Cd}$ did not affect significantly the Fulton of females $(\mathrm{K}=0.737 \pm 0.08$ and $0.712 \pm$ 0.08 for $\mathrm{C}$ and $\mathrm{Cd}$ females respectively, $\mathrm{P}=0.194$, Tukey's HSD test), Cd triggered a significant decrease of this index in males $(K=0.745 \pm 0.08$ and $0.659 \pm 0.08$ for $\mathrm{C}$ and $\mathrm{Cd}$ males respectively, $\mathrm{n}=111-115, \mathrm{P}<0.001$, Tukey's HSD test). This suggests a higher sensitivity of males to $\mathrm{Cd}$. In the same view, high density can represent stressing conditions, producing more females at the next generation, i.e. individuals that were found to be less sensitive to stress in comparison to males in zebrafish (40 Rambo et al., 2017), can represent a strategy to maximize the fitness of their offspring. Indeed, Rambo et al. (40 2017) have reported gender difference on behavioral parameters and cortisol levels in response to unpredictable chronic stress (UCS) in zebrafish. While UCS triggered an increase in both the aggressive behavior and in cortisol levels in males, no significant effects were observed in females. More generally, feminization is usually expected to boost population growth (3 Wedekind, 2017).

Another interesting point of our results relies on the fact that the effect of $\mathrm{Cd}$ on the methylation level of foxl $2 a$ was observed on three successive generations (F0, F1 and F2). For recall, only zebrafish of the F0 generation were exposed to $\mathrm{Cd}$. If a direct effect of $\mathrm{Cd}$ at the F1 generation cannot be excluded due to a potential transfer of metal via the gametes (notably via oocytes and vitellogenin, 27 Pierron et al. 2008), such an effect appears difficult to conceive at the generation F2 (notably due to growth dilution). Recent discoveries (15-16 Ortega-Recalde et al. (2019), Skvortsova et al. (2019)) have reported that, in stark contrast to mammals, germline of zebrafish does not undergo genome-wide erasure of DNA methylation at any stage of development, from $4 \mathrm{hpf}$ until sexual maturity. Such results could be explained, at least in part by the fact that, in contrast to mammals, zebrafish have a 'preformed' germline whereby primordial germ cells (PGCs) are specified by cytoplasmic determinants called germplasm that were produced during oogenesis; i.e. these determinants 
are maternally provided. These recent studies can thus support transgenerational inheritance of stress-induced changes in DNA methylation marks. In our case, the effect of $\mathrm{Cd}$ on the methylation levels of foxl $2 a$ in female gonads was no more observed at the generation F3, suggesting a potential reset of $\mathrm{Cd}$-induced epigenetic effect at the fourth generation. However, this reset coincided with the effect of density on the methylation level of the couple foxl2aldmrt1 at the F2 generation. Thus, a potential transfer of Cd-induced changes in the methylation level of foxl $2 a$ beyond the third generation cannot be ruled out. In this view, we must add that the significant effect of density on the methylation level of $d m r t 1$ observed in control females of the generation F2 was no more observed at the generation F3. The question of transgenerational inheritance of stress-induced DNA methylation changes appears to be far from simple, appearing to be sex-dependent and involving undoubtedly other genes and mechanisms.

Finally, as our conclusions were mainly drawn from correlation analyses, cautions must obviously be taken. In this view, we must note that our results were obtained from a gonad sample containing several oocytes. A way to better understand the link between female gonad methylation and the offspring SR could be to analyze the methylation level of individual eggs. Oocytes/eggs from a single female could indeed present very different levels of methylation. In other words, each egg could contain not only the genetic but also the epigenetic information that would induce the phenotypic sex of the individual to which it will give birth after fertilization. This could explain why very strong correlations were observed between the methylation state of female gonads and the SR of the entire population while weak or moderate effects were recorded among fish groups (i.e. when mean values are compared). More generally, in a context of global change, it appears urgent to better characterize stress-induced changes in epigenetic marks and their phenotypic impacts as our results tend to show that such modifications can not only affect transgenerationally the plasticity of individuals but also the sex ratio of populations. Such stress-induced changes and genotype-phenotype mismatches can indeed have long-lasting effects on population demography, genetics and viability (3 Wedekind, 2017).

\section{Material and Methods}

\section{General rearing and breeding program}

Wild-type adult mature danios were purchased from a commercial vendor (Hâpyfish, France). Wild-type (domesticated) zebrafish were preferred to laboratory-bred lines as a previous work reported an effect of inbreeding and loss of genetic polymorphism on the transcriptomic response of zebrafish to metal exposure (42-43 Gentès et al., 2015; Gurvey et al., 2006). After 3 months of acclimation under rearing conditions, one male and one female (one pair) were randomly placed in a small breeding tank $(2 \mathrm{~L})$ in the afternoon. A total of 40 pairs were used, 20 pairs for the $\mathrm{C}$ condition and 20 for the $\mathrm{Cd}$ condition. Indeed, at this time $\mathrm{Cd}$ exposure began. As reproduction occurs the next morning, genitors (F-1) were exposed only one night to Cd. Eggs and larvae were raised in breeding tanks until $14 \mathrm{dpf}$. From the $5^{\text {th }}$ day, larvae were fed ad libitum 2 times daily with live Artemia nauplii, infusoria and dry flakes (Tetramin baby). Water was changed 2 times daily by means of a drip system adding clean or Cd-contaminated water. At $14 \mathrm{dpf}$, juveniles were placed in 4 large tanks $(75 \mathrm{~L})$ per condition permanently supplied with water (flow rate $6.5 \mathrm{ml} . \mathrm{min}^{-1}$ ). In the case of Cdcontaminated fish, this water was contaminated by means of a peristaltic pump which added $\mathrm{Cd}$ at the desired concentration. The use of a flow-through system aimed maintaining water 
quality throughout the experiment among tanks. Indeed, all tanks were supplied with water providing from a single reservoir. Water in the reservoir was treated (filtered, aerated, heated and $\mathrm{pH}$ was regulated by adding $\mathrm{CO}_{2}$ ) before to be distributed to tanks. Fish were fed two times daily with live Artemia nauplii and one time with dry granules (Tetramin). At $124 \mathrm{dpf}$, 20 individuals per sex and condition were sampled and dissected. Samples for DNA methylation and transcription analyses were fixed in RNAlater solution before to be stored at $-20^{\circ} \mathrm{C}$. At $170 \mathrm{dpf}, 20$ pairs per condition were constituted to produce the next generation. We must note that pairs were not fully randomly constituted. As all individuals from one clutch (i.e. from one pair) were raised in the same large tank, one male from one tank was mated with a female from another tank. The aim was to limit consanguinity, genetic drift and inbreeding depression. All remaining individuals after mating were measured and weighted to estimate the Fulton condition factor $\left[\mathrm{K}=(\right.$ total weight $\left.\left.(\mathrm{g})) /(\text { total length }(\mathrm{cm}))^{3}\right) \times 10^{5}\right]$ and sexed by dissection and visual inspection under binocular. $\mathrm{Cd}$ concentration in water was determined as described in 28 Pierron et al. 2014. The average concentrations were $0.049 \pm$ $0.004 \mu \mathrm{g} . \mathrm{L}^{-1}$ and $0.987 \pm 0.025 \mu \mathrm{g} . \mathrm{L}^{-1}($ mean $\pm \mathrm{SE}, \mathrm{n}=260)$ in control and contaminated tanks, respectively. The same protocol as previously described was used for mating and sample collection for the F1, F2 and F3 generations. However, for both groups of animals (controls and Cd), spawning was carried out in Cd-free water. Throughout the experiment, the light-dark cycle was controlled and fixed at 14-hour light and 10-hour dark. Temperature and $\mathrm{pH}$ in tanks were recorded daily. Temperature in $\mathrm{C}$ and $\mathrm{Cd}$ tanks reached $27.72 \pm 0.60$ and $27.70 \pm 0.64$ (mean $\pm \mathrm{SD}$ ), respectively. Mean values of $\mathrm{pH}$ in control and $\mathrm{Cd}$ tanks were 7.91 \pm 0.16 and $7.92 \pm 0.15$ (mean $\pm \mathrm{SD}$ ), respectively. Total duration of the experience was 643 days.

For the F0 and F2 generation, at 14 dpf, 75 juveniles were randomly chosen from different mating pairs and were placed in large tank $(75 \mathrm{~L})$ to be raised at a nominal temperature of $34^{\circ} \mathrm{C}$. With exception to the temperature, the same rearing conditions as previously described were used. All these fish were dissected for analysis at $130 \mathrm{dpf}$. Temperature in control and Cd tanks reached $34.44 \pm 0.47$ and $34.48 \pm 0.47$ (mean $\pm \mathrm{SD}$ ), respectively.

No significant differences were observed regarding the survival rates between the control and the treatment groups. Mortality at the adult stage was less than $1 \%$ at $27.7^{\circ} \mathrm{C}$ and ranged from 4.0 to $7.5 \%$ at $34^{\circ} \mathrm{C}$. Cannibalism was observed until $60 \mathrm{dpf}$ (personal observation).

The SR was calculated as follow: (number of males/total number of individuals) $\mathrm{x}$ 100.

All procedures used in this experiment were approved by the Aquitaine fish-birds ethic committee (APAFIS\#7535-2016111009351504).

\section{Quantitative analysis of methylation levels}

Genomic sequences were obtained from the Genome Reference Consortium Zebrafish (GRCz11). Specific primer used for PCR amplification and sequencing were designed in the promoter region of genes by means of the Pyromark assay design software (Table S1).

A total of 6 control or Cd fish at $124 \mathrm{dpf}$ were used per sex and generation. For the HT condition, due to higher variability, 8 fish at $130 \mathrm{dpf}$ were used per condition $(\mathrm{C}$ or $\mathrm{Cd})$ and generation. However, due to masculinization of the population, only $5 \mathrm{CHT}$ females could be obtained and used. For each fish, DNA and RNA were extracted using the AllPrep DNA/RNA kit (Qiagen) as previously described in 44 Pierron et al. (2019). Quantification of single cytosine percent methylation at specific sites was then performed using the bisulfite- 
pyrosequencing method. First, $500 \mathrm{ng}$ of DNA were bisulfite converted using the MethylEdge Bisulfite Conversion System (Promega) according to manufactures' guidelines. Then, $1 \mu \mathrm{l}$ of bisulfite converted DNA was amplified by PCR using the PyroMark PCR kit (Qiagen) denaturation step at $95{ }^{\circ} \mathrm{C}$, followed by 45 cycles of $94{ }^{\circ} \mathrm{C}$ for $30 \mathrm{~s}, 56{ }^{\circ} \mathrm{C}$ for $30 \mathrm{~s}, 72{ }^{\circ} \mathrm{C}$ for $30,10 \mathrm{~min}$ of final elongation at $72{ }^{\circ} \mathrm{C}$. Pyrosequencing of biotinylated PCR products was performed by means of the PyroMark Q48 Autoprep (Qiagen). Average DNA methylation levels of $\mathrm{CpG}$ sites were quantified using the PyroMark Q48 autoprep software (Qiagen). As a similar pattern was observed for all $\mathrm{CpG}$ analyzed and as the fluorescence progressively decreases during the sequencing run, only the methylation percent of two first $\mathrm{CpG}$ sites were used in subsequent analyses. For example, for cyp19ala, the mean methylation levels determined in the first two CpG sites was highly correlated with the mean methylation levels determined using all the six $\mathrm{CpG}$ analyzed $(\mathrm{r}=0.998, \mathrm{P}<0.0001$; Fig. S4). The aim was to use the most accurate results.

In addition, for cyp19ala, in order to assay the conversion efficiency of the bisulfite treatment the average methylation level of one CpA site was measured. The methylation level of this control site was always undetectable, indicating very good conversion efficiency. Examples of pyrograms as well as further details are available in Fig. S5.

The same protocol was used for larvae ( $5 \mathrm{dpf}, \mathrm{n}=6$ per condition and generation). DNA was extracted from a single whole larva. Twenty $\mu$ l of DNA were bisulfite converted.

\section{Quantitative analysis of transcription levels}

RT-qPCR analyses were carried out as previously described in 44 Pierron et al. (2019) with few modifications. First-strand cDNA was synthesized from 250 and $500 \mathrm{ng}$ of total RNA for male and female respectively. Following the reverse transcriptase reaction, cDNA was diluted 8- and 16-fold from male and female respectively. Relative quantification of gene transcription was achieved by concurrent amplification of the actb1, eeflala and rpll3a endogenous controls (45 McCurley and Callard, 2008). Hence, during our experiment, total RNAs were quantified and the same quantity was used to be reverse-transcribed. During the subsequent qPCR amplifications, the output cycle of the endogenous controls were examined. Contrary to $a c t b 1$ (sex-specific), no significant difference was observed on the output cycle of eeflala and rpll3a among fish. The mean $\mathrm{Ct}$ value of the two latter genes was used as reference. Primers used are available in Table S1.

\section{Statistical analyses}

Due to the bimodal distribution of data from females and males, the effect of sex on DNA methylation or transcription levels was analyzed by means of the nonparametric MannWhitney test. Then, data from each sex were analyzed separately. Comparisons among fish groups of the same sex were performed by two (Generation and $\mathrm{Cd}$ ) or three-ways (including HT for F0 and F2 generations only) analysis of variance (ANOVA), after checking assumptions of normality (Kolmogorov-Smirnov) and homoscedasticity of the error terms (Levene). If significant effects were detected, the Bonferroni test was used to determine the effect of each individual factor. When the assumptions were not met as deduced from ad-hoc tests, we used box-cox data transformations or nonparametric Kruskal-Wallis test. The Tukey's HSD test or the Dunn test with Bonferroni correction were used to determine whether means between pairs of samples were significantly different from one another. 
Comparisons of proportions (SR) were performed using the Chi squared test and the Monte Carlo method using 5000 permutations followed by the Marascuilo procedure to compare proportions among them. Computations were performed using STATISTICA version 6.1 software (StatSoft) and XLSTAT (Addinsoft version 2020.1.1). Numerical results are given as means $\pm \mathrm{SE}$.

\section{Acknowledgments}

Mohamedou Sow is thanked for his advices on statistical analyses. Christian Portier, Kévin Lebaillif and Jacques Martin are thanked for their technical help with the experimental setup. This work was supported by the Agence Nationale de la Recherche of France (ANR JCJC TRACE ANR-16-CE34-0008).

\section{References}

1. S.A. West, S.E. Reece, B.C. Sheldon. Sex ratios. Heredity. 88, 117-124 (2002).

2. C. Wedekind. Managing Population Sex Ratios in Conservation Practice: How and Why?, In Topics in Conservation Biology, T. Povilitis Ed. (InTech, 2012), pp. 81-96.

3. C. Wedekind. Demographic and genetic consequences of disturbed sex determination. Philos Trans R Soc Lond B Biol Sci. 372(1729):20160326 (2017).

4. B. Capel. Vertebrate sex determination: evolutionary plasticity of a fundamental switch. Nat. Rev. Genet. 18(11):675-689 (2017).

5. C. Shao, Q. Li, S. Chen, P. Zhang, J. Lian, Q. Hu, B. Sun, L. Jin, S. Liu, Z. Wang, H. Zhao, Z. Jin, Z. Liang, Y. Li, Q. Zheng, Y. Zhang, J. Wang, G. Zhang. Epigenetic modification and inheritance in sexual reversal of fish. Genome Res. 24(4):604-615 (2014).

6. L. Navarro-Martín, J. Viñas, L. Ribas, N. Díaz, A. Gutiérrez, L. Di Croce, F. Piferrer . DNA methylation of the gonadal aromatase (cyp19a) promoter is involved in temperature-dependent sex ratio shifts in the European sea bass. PLoS Genet. 7(12):e1002447 (2011).

7. R. Feil, M.F. Fraga. Epigenetics and the environment: emerging patterns and implications. Nat. Rev. Genet. 13(2):97-109 (2012).

8. C.J. Harris, M. Scheibe, S.P. Wongpalee, et al. A DNA methylation reader complex that enhances gene transcription. Science. 362(6419):1182-1186 (2018).

9. S.S. Hammoud, D.H. Low, C. Yi, D.T. Carrell, E. Guccione, B.R. Cairns. Chromatin and transcription transitions of mammalian adult germline stem cells and spermatogenesis. Cell Stem Cell. 7, 239-253 (2014).

10. F. Piferrer. Epigenetics of sex determination and gonadogenesis. Dev Dyn. 242(4):360-370 (2013).

11. J.A. Head, D.C. Dolinoy, B. Niladri. Epigenetics for ecotoxicologists. Environ. Toxicol. Chem. 31 (2), 221-227 (2012).

12. R. Jaenisch, A. Bird. Epigenetic regulation of gene expression: how the genome integrates intrinsic and environmental signals. Nat. Genetics. 33, 245-254 (2003).

13. R. Kucharski, J. Maleszka, S. Foret, R. Maleszka. Nutritional control of reproductive status in honeybees via DNA methylation. Science. 319, 1827-1830 (2008).

14. E. Heard, R.A. Martienssen. Transgenerational epigenetic inheritance: myths and mechanisms. Cell. 157(1):95-109 (2014). 
15. O. Ortega-Recalde, R.C. Day, N.J. Gemmell, T.A. Hore. Zebrafish preserve global germline DNA methylation while sex-linked rDNA is amplified and demethylated during feminisation. Nat Commun. 10, 3053 (2019).

16. K. Skvortsova, K. Tarbashevich, M. Stehling, R. Lister, M. Irimia, E. Raz, O. Bogdanovic. Retention of paternal DNA methylome in the developing zebrafish germline. Nat Commun. 10, 3054 (2019).

17. G. Fusco, A. Minelli. Phenotypic plasticity in development and evolution: facts and concepts. Phil. Trans. R. Soc. B. 365, 547-556 (2010).

18. R.-J. Spencer, F.J. Janzen. A novel hypothesis for the adaptive maintenance of environmental sex determination in a turtle. Proc. R. Soc. B. 281, 20140831 (2016).

19. J. Komdeur, S. Daan, J. Tinbergen, C. Mateman Extreme adaptive modification in sex ratio of the Seychelles warbler's eggs. Nature. 385, 522-525 (1997).

20. G. Schino, Birth sex ratio and social rank: consistency and variability within and between primate groups. Behav. Ecol.15(5):850-856 (2004).

21. W.C. Liew, L. Orbán. Zebrafish sex: a complicated affair. Brief Funct. Genomics. 13(2):172-187 (2014).

22. A. Nagabhushana, R.K. Mishra. Finding clues to the riddle of sex determination in zebrafish. J Biosci. 41, 145-155 (2016).

23. D. Santos, A. Luzio, A.M. Coimbra. Zebrafish sex differentiation and gonad development: A review on the impact of environmental factors. Aquat Toxicol. 191:141-163 (2017).

24. D. Uchida, M. Yamashita, T. Kitano, T. Iguchi. An aromatase inhibitor or high water temperature induce oocyte apoptosis and depletion of P450 aromatase activity in the gonads of genetic female zebrafish during sex-reversal. Comp. Biochem. Physiol. A Mol. Integr. Physiol. 137(1):11-20 (2004).

25. L. Ribas, K. Vanezis, M.A. Imués, F. Piferrer. Treatment with a DNA methyltransferase inhibitor feminizes zebrafish and induces long-term expression changes in the gonads. Epigenetics Chromatin. 10(1):59 (2017).

26. A. Kortenkamp. Are cadmium and other heavy metal compounds acting as endocrine disrupters?. Met Ions Life Sci. 8:305-317 (2011).

27. F. Pierron, M. Baudrimont, S. Dufour, P. Elie, A. Bossy, S. Baloche, N. MesmerDudons, P. Gonzalez, J.-P. Bourdineaud, J.-C. Massabuau. How cadmium could compromise the completion of the European eel's reproductive migration. Environ. Sci. Technol. 42:4607-4612 (2008).

28. F. Pierron, L. Baillon, M. Sow, S. Gotreau, P. Gonzalez. Effect of low-dose cadmium exposure on DNA methylation in the endangered European eel. Environ. Sci. Technol.48 (1):797-803 (2014).

29. G. Kelsey, R. Feil. New insights into establishment and maintenance of DNA methylation imprints in mammals. Philos. Trans. R. Soc. Lond. B Biol. Sci. 368(1609):20110336 (2013).

30. Y.-J. Yang, Y. Wang, Z. Li, J.-F. Gui. Sequential, divergent and cooperative requirements of Foxl2a and Foxl2b in ovary development and maintenance of zebrafish. Genetics, 205, 1551- 1572 (2017).

31. K.A. Webster, U. Schach, A. Ordaz, J.S. Steinfeld, B.W. Draper, K.R. Siegfried. Dmrt1 is necessary for male sexual development in zebrafish. Dev. Biol. 422(1):33-46 (2017).

32. P. Couture, P. Busby, C. Gauthier, J.W. Rajotte, G.G. Pyle. Seasonal and regional variations of metal contamination and condition indicators in yellow perch (Perca 
flavescens) along two polymetallic gradients. I. Factors influencing tissue metal concentrations. Hum. Ecol. Risk Assess. 14 (1):97-125 (2008).

33. L.V. Laing, J. Viana, E.L. Dempster, T.M. Uren Webster, R. van Aerle, J. Mill, E.M. Santos. Sex-specific transcription and DNA methylation profiles of reproductive and epigenetic associated genes in the gonads and livers of breeding zebrafish. Comp Biochem Physiol A. Mol. Integr. Physiol. 222:16-25 (2018).

34. J.A. Domingos, A.M. Budd, Q.Q. Banh, J.A. Goldsbury, K.R. Zenger, D.R. Jerry. Sex-specific dmrtl and cyp19al methylation and alternative splicing in gonads of the protandrous hermaphrodite barramundi. PLoS ONE. 13(9): e0204182 (2018).

35. D. Anastasiadi, M. Vandeputte, N. Sánchez-Baizán, F. Allal, E. Piferrer. Dynamic epimarks in sex-related genes predict gonad phenotype in the European sea bass, a fish with mixed genetic and environmental sex determination. Epigenetics. 13(9):988-1011 (2018).

36. Z. Fan, Y. Zou, D. Liang, X. Tan, S. Jiao, Z. Wu, J. Li, P. Zhang, F. You. Roles of forkhead box protein L2 (foxl2) during gonad differentiation and maintenance in a fish, the olive flounder (Paralichthys olivaceus). Reprod. Fertil. Dev. 31(11):17421752 (2019).

37. X. Zhang, M. Li, H. Ma, X. Liu, H. Shi, M. Li, D. Wang. Mutation of foxl2 or cyp19ala Results in Female to Male Sex Reversal in XX Nile Tilapia. Endocrinology. 158(8):2634-2647 (2017).

38. Y. Si, Y. Ding, F. He, H. Wen, J. Li, J. Zhao, Z. Huang. DNA methylation level of cyp19a1a and Foxl2 gene related to their expression patterns and reproduction traits during ovary development stages of Japanese flounder (Paralichthys olivaceus). Gene. 575(2):321-330 (2016).

39. S. Huang, L. Ye, H. Chen. Sex determination and maintenance: the role of DMRT1 and FOXL2. Asian J. Androl.19(6):619-624 (2017).

40. R. Li, L. Zhang, W. Li, Y. Zhang, Y. Li, M. Zhang, L. Zhao, X. Hu, S. Wang, Z. Bao. FOXL2 and DMRT1L Are Yin and Yang Genes for Determining Timing of Sex Differentiation in the Bivalve Mollusk Patinopecten yessoensis. Front. Physiol. 9:1166 (2018).

41. C.L. Rambo, R. Mocelin, M. Marcon, D. Villanova, G. Koakoski, M.S. de Abreu, T.A. Oliveira, L.J.G. Barcellos, A.L. Piato, C.D. Bonan. Gender differences in aggression and cortisol levels in zebrafish subjected to unpredictable chronic stress. Physiol. Behav. 171:50-54 (2017).

42. S. Gentès, R. Maury-Brachet, C. Feng, Z. Pedrero, E. Tessier, A. Legeay, N. MesmerDudons, M. Baudrimont, L. Maurice, D. Amouroux, P. Gonzalez . Specific Effects of Dietary Methylmercury and Inorganic Mercury in Zebrafish (Danio rerio) Determined by Genetic, Histological, and Metallothionein Responses. Environ. Sci. Technol. 49(24):14560-14569 (2015).

43. V. Guryev, M.J. Koudijs, E. Berezikov, S.L. Johnson, R.H. Plasterk, F.J. van Eeden, E. Cuppen. Genetic variation in the zebrafish. Genome Res. 16, 491-497 (2006).

44. F. Pierron, G. Daffe, P. Lambert, P. Couture, M. Baudrimont. Retrotransposon methylation and activity in wild fish (A. anguilla): a matter of size. Environmen. Pollut. 245, 494-503 (2019).

45. A.T. McCurley, G.V. Callard. Characterization of housekeeping genes in zebrafish: male-female differences and effects of tissue type, developmental stage and chemical treatment. BMC Mol Biol. 9:102 (2008). 


\section{Figures}

Figure 1. Synoptic of the experimental design.

743 Only fish of the F0 generation were exposed to cadmium (Cd) throughout their life (0 to 169 $\mathrm{dpf}$ ). Their parents (F-1) were exposed only one night to $\mathrm{Cd}$. At each generation, 20 mating pairs and 4 experimental units were used per condition $(\mathrm{C}$, control; $\mathrm{Cd}$, cadmium). At the $\mathrm{F} 0$ and F2 generations, a subset of individuals was raised at an elevated temperature $\left(34^{\circ} \mathrm{C}, 14\right.$ to $130 \mathrm{dpf}$ ). See Material and Methods for more details.

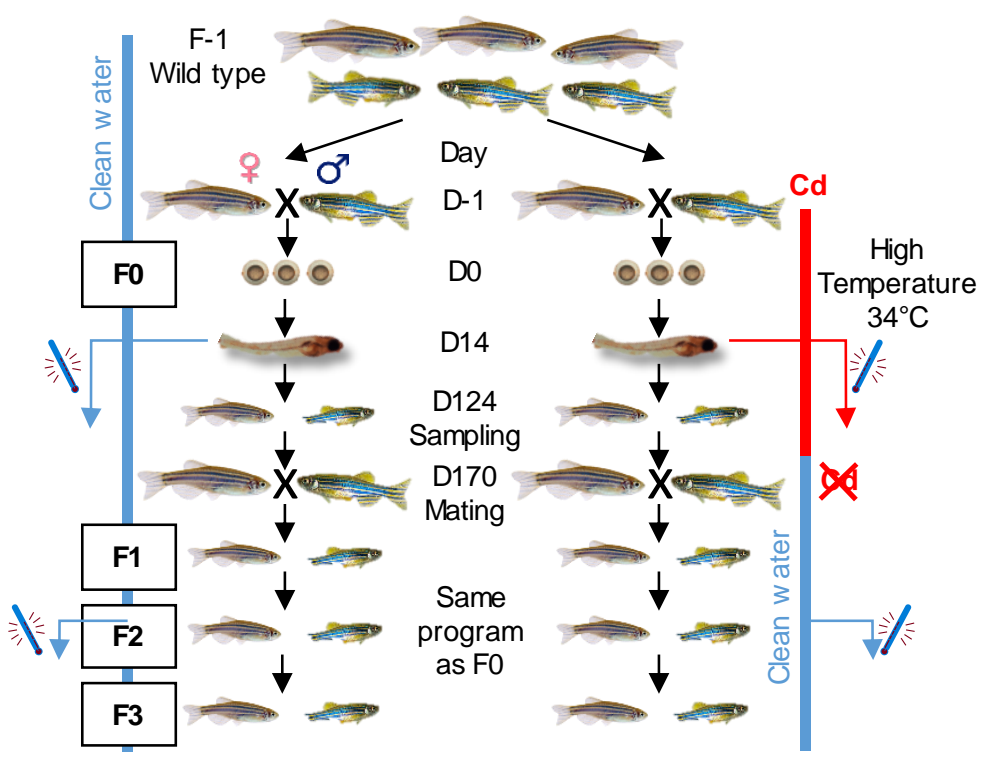


Figure 2. Direct or ancestral exposure to $\mathrm{Cd}$ affects the sex ratio.

753 Change in the sex ratio across generations (F0 to $\mathrm{F} 3$ ) in response to cadmium (Cd) and/or

754 high temperature $(\mathrm{HT})$ exposure. Means $( \pm \mathrm{SE}, \mathrm{n}=4)$ designated with different letters are 755 significantly different $(\mathrm{P}<0.05$, Marascuilo procedure). Sex ratio was calculated as follow: 756 (number of males/total number of individuals) $\mathrm{x} 100$.

757

758

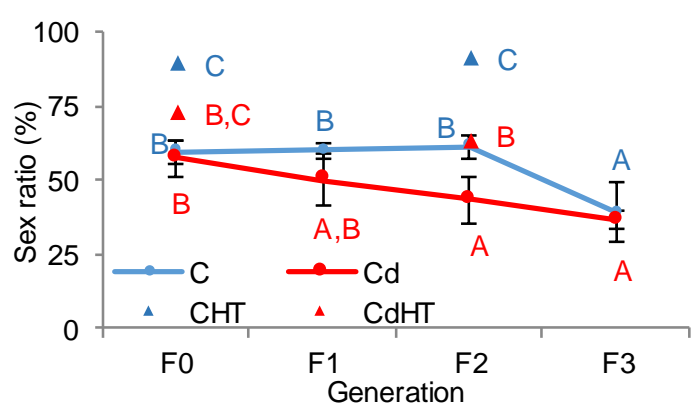


Figure 3. Sex-specific DNA methylation and RNA transcription profiles.

(A) DNA methylation and transcription levels (mean $\pm \mathrm{SE}, \mathrm{n}=5-8$ ) of cyp19ala, foxl2a and dmrt1 in gonads of female and male zebrafish from each generation (F0 to F3) and from the different experimental conditions: $\mathrm{C}$, control (blue); $\mathrm{Cd}$, cadmium (red); $28^{\circ} \mathrm{C}$ and $34^{\circ} \mathrm{C}$ (i.e. high temperature). For more clarity, only the significant effect of sex (Mann-Whitney test) and of $\mathrm{Cd}$ and high temperature (Bonferroni test) are indicated: $* \mathrm{P}<0.05 ; * * \mathrm{P}<0.01$; $* * * \mathrm{P}<0.001$ and $* * * * \mathrm{P}<0.0001$. (B) Normal density distribution of the promoter methylation levels of cyp19ala, foxl $2 a$ and dmrtl in gonads of female and male zebrafish from the different experimental conditions: F, female; $\mathrm{M}$, male; $\mathrm{C}$, control; $\mathrm{Cd}$, cadmium; HT, high temperature. Raw data are available in figure $\mathrm{S} 1$.

A DNA methylation (\%)
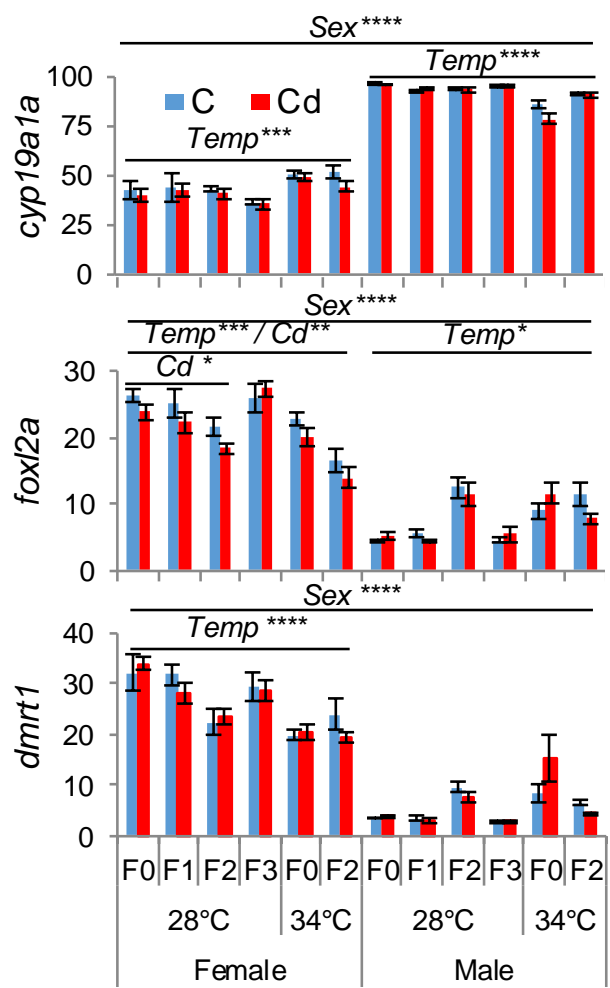

Gene transcription (a.u.) Sex ${ }^{* \star \star \star}$

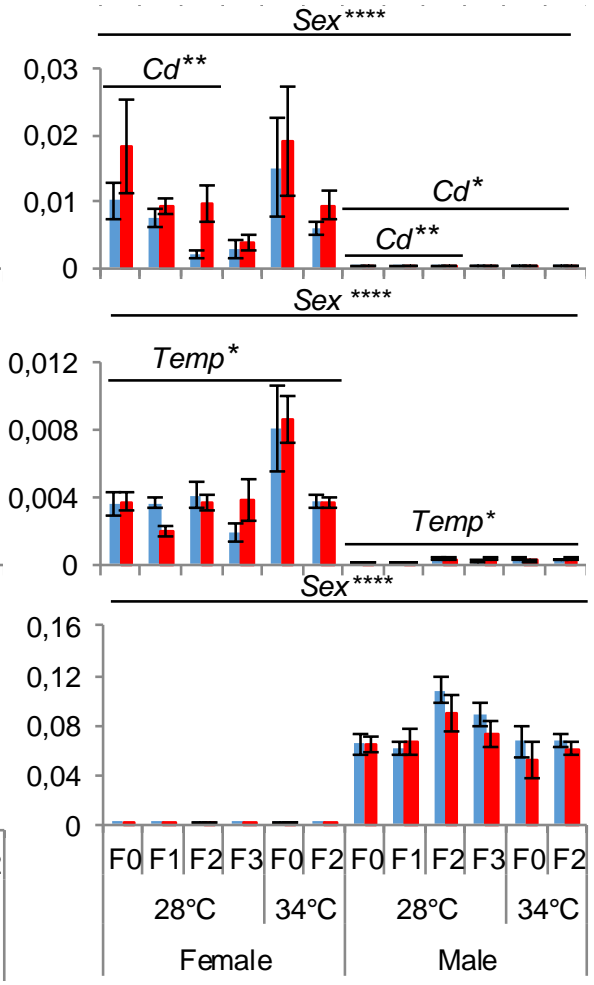

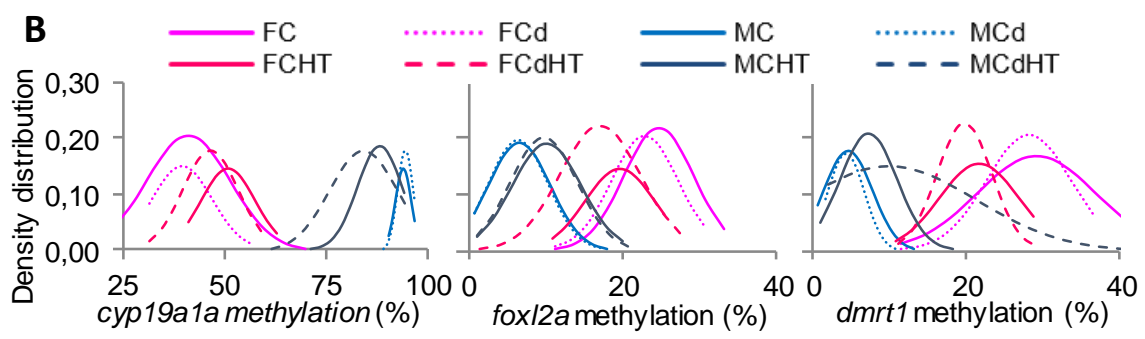


Figure 4. foxl2a/dmrtl function in a Yin and Yang relationship

Relationships between foxl2a and $d m r t 1$ at (A) the promoter DNA methylation level (\%) and at (B) the transcriptional level (a.u.). The Pearson correlation coefficient (r) and the associated $P$ value are reported, $n=154$. F, female; $M$, male; $C$, control; $C d$, cadmium; HT, high temperature.

777

\section{A}
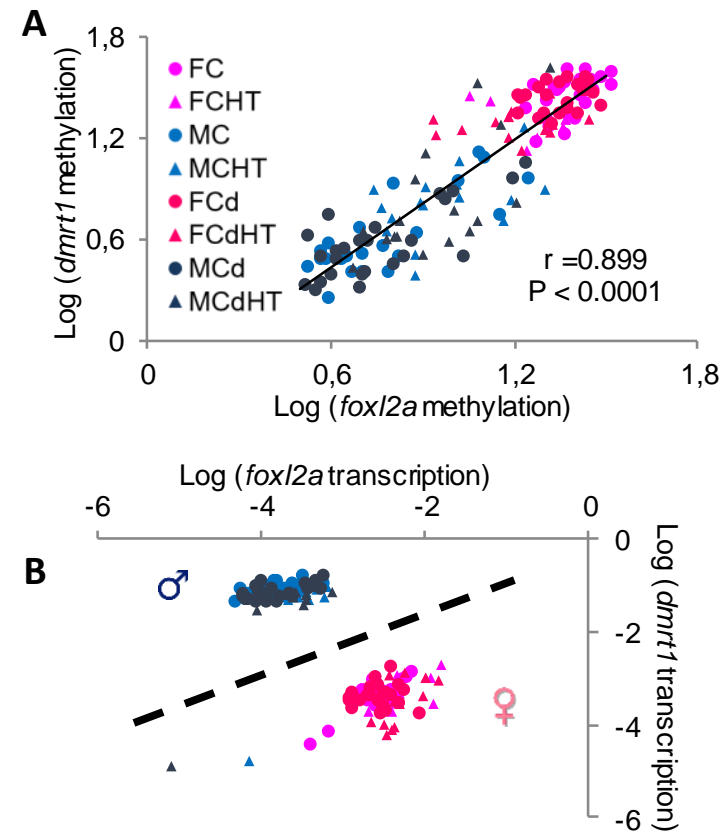
Figure 5. Female gonad methylation influences the sex ratio of the population.

(A) Relationship between the mean methylation level of cyp19ala in females $(\mathrm{n}=5-8)$ of each generation (F) and the sex ratio. (B) Relationship between the mean methylation level of foxl2 $a$ in females $(n=6)$ of each generation $(F)$ and the sex ratio at the next generation $(F+1)$. (C) Relationship between the mean methylation level $(\mathrm{n}=6)$ of foxl2a in female gonads of each generation $(F)$ and the mean methylation level of cyp19ala in whole larvae $(n=6)$ of the next generation $(\mathrm{F}+1)$. $(\mathbf{A})(\mathbf{B})(\mathbf{C})$ The Pearson correlation coefficient $(\mathrm{r})$ and the associated $\mathrm{P}$ value are reported. For $(\mathbf{B})$ and $(\mathbf{C})$ while the generation $(\mathrm{F})$ indicated under the regression line refers to the variable of the $\mathrm{x}$ axis, the generation indicated above refers to the variable of the y axis. C, control; Cd, cadmium; HT, high temperature

789

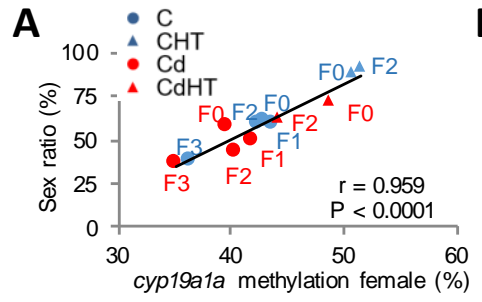

790
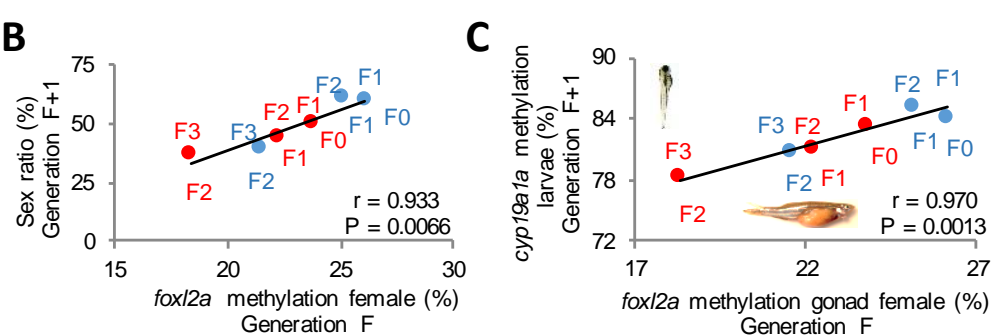
Figure 6. Influence of fish density on the methylation level of the couple foxl2aldmrt1. Relationship between the mean methylation level $(\mathrm{n}=6)$ of $(\mathbf{A})$ foxl2a or (B) dmrtl in female gonads of each generation with fish density (mean $\pm S E, n=4$ ). The Pearson correlation coefficients (r) and the associated $\mathrm{P}$ values are indicated.

795
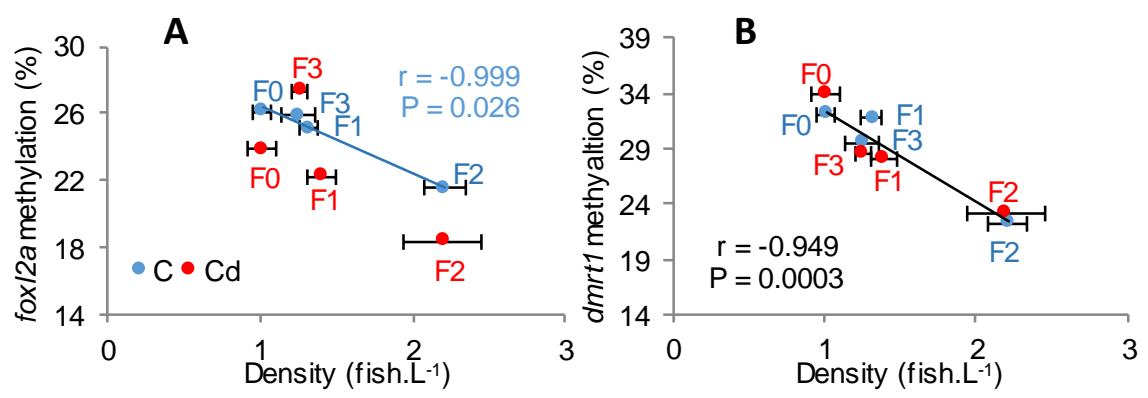